\title{
PEMAHAMAN GURU TERHADAP PESERTA DIDIK BERKEBUTUHAN KHUSUS DI SEKOLAH DASAR INKLUSIF WILAYAH KEPULAUAN SERIBU
}

\author{
Siti Nurul Komariyah ${ }^{1}$, Riana Bagaskorowati ${ }^{2}$, Leliana Lianty ${ }^{3}$ \\ Pendidikan Luar Biasa Fakultas Ilmu Pendidikan Universitas Negeri Jakarta \\ Email: snurulkomariyah@gmail.com,riana_gunadi@yahoo.com, lelianalianty@gmail.com
}

\begin{abstract}
This study aims to empirical related understanding to update the data they think of students with special needs in primary schools inclusive kepulauan seribu. Sample of the research is teachers SDN 01 panggang island, teachers of SDN 02 panggang island and teachers sdn 03 panggang island Kepulauan Seribu some 50 people. This approach in this study used a quantitative approach with the descriptive. Data collection in this research using survey by the questionnaire as an instrument used to collect data from respondents.Study was conducted in SDN inclusive in Kepulauan Seribu. The research results show that they think of understanding students with special needs in sdn inclusive kepulauan seribu has not been spread evenly. This can be seen from the acquisition a score respondents a whole that a lot of teachers who are already proficient in ideal and have a score above the limit those teachers ( $72 \%$ ). But there is some of the teachers did not understand school tuition berkebutuhan special and have a score under the ideal the 14 teachers ( $28 \%$ ).Based on the results of that research shows that understanding teachers for participants students special berkebutuhan in primary schools inclusive kepulauan seribu has not been spread evenly, so this might impact on the implementation of the teaching and learning done that school tuition berkebutuhan special not fully served well
\end{abstract}

Keyword : Understanding Teachers, an Inclusive School, Students with special needs.

\begin{abstract}
Abstrak
Penelitian ini bertujuan untuk memperoleh data empirik terkait pemahaman guru terhadap peserta didik berkebutuhan khusus di SD Inklusif wilayah Kepulauan Seribu. Sampel dalam penelitian ini adalah guru SDN 01 Pulau Panggang, guru SDN 02 Pulau Panggang dan guru SDN 03 Pulau Panggang Kepulauan Seribu sebanyak 50 orang. Pendekatan dalam penelitian ini menggunakan pendekatan kuantitatif dengan metode deskriptif. Pengumpulan data dalam penelitian ini menggunakan survei dengan kuesioner sebagai alat yang digunakan untuk mengumpulkan data dari responden. Penelitian ini dilaksanakan di SDN Inklusif di Kepulauan Seribu. Hasil penelitian menunjukkan bahwa pemahaman guru terhadap peserta didik berkebutuhan khusus di SDN Inklusif wilayah Kepulauan Seribu belum merata. Hal ini dapat dilihat dari pemerolehan skor responden keseluruhan bahwa banyak guru yang sudah memahami dan memiliki skor diatas batas ideal yaitu sebanyak 36 orang guru (72\%). Namun ada beberapa guru yang belum memahami peserta didik berkebutuhan khusus dan memiliki skor dibawah batas ideal sebanyak 14 orang guru (28\%). Berdasarkan hasil penelitian yang menunjukkan bahwa pemahaman guru terhadap peserta didik berkebutuhan khusus di SD Inklusif wilayah Kepulauan Seribu belum merata, maka hal ini berdampak pada pelaksanaan belajar mengajar yang dilakukan bahwa peserta didik berkebutuhan khusus belum sepenuhnya terlayani dengan baik.
\end{abstract}

Kata kunci: Pemahaman Guru, Sekolah Inklusif, Peserta Didik Berkebutuhan Khusus.

\section{PENDAHULUAN}

Sekolah inklusif adalah sekolah reguler yang dapat menerima peserta didik berkebutuhan khusus. Ketika sekolah reguler menjadi sekolah inklusif, maka semua yang berada dalam sekolah tersebut harus sudah siap dengan kedatangan peserta didik berkebutuhan khusus. Dalam pengaplikasiannya sekolah inklusif harus memiliki persiapan matang, baik dari 
kepala sekolah, guru, sarana prasarana, dan kurikulum. Peranan guru adalah salah satu hal penting dalam sekolah inklusif, karena guru akan melayani, mengajar dan mendidik peserta didik berkebutuhan khusus yang datang ke sekolah inklusif. Maka dari itu guru di sekolah inklusif perlu mendapatkan pengetahuan tentang peserta didik berkebutuhan khusus agar memahami kebutuhan dan karakteristik dari peserta didik berkebutuhan khusus sehingga anak berkebutuhan khusus mendapatkan layanan pendidikan yang sesuai dengan kebutuhannya.

Pemahaman guru terhadap peserta didik berkebutuhan khusus dalam sekolah penyelenggara pendidikan inklusi dapat mencerminkan kualitas dari sekolah inklusif. Pemahaman guru yang kurang terhadap layanan pendidikan yang cocok untuk peserta didik berkebutuhan khusus akan membuat guru kesulitan untuk memberikan pembelajaran kepada peserta didik berkebutuhan khusus. Guru yang memiliki pemahaman kurang terhadap peserta didik berkebutuhan khusus mengakibatkan peserta didik berkebutuhan khusus tidak mendapat layanan pendidikan sesuai kebutuhannya. Maka dari itu guru harus memiliki pemahaman yang baik terhadap anak berkebutuhan khusus agar mereka dapat terlayani dengan baik.

Di salah satu SD penyelenggara inklusif wilayah Kepulauan Seribu yang peneliti observasi, terdapat lima anak berkebutuhan khusus dengan hambatan berbeda yang terbagi di beberapa kelas. Ketika peneliti melihat proses pembelajaran di dalam kelas, guru di sekolah tersebut ada yang memberikan layanan pendidikan yang belum baik terhadap peserta didik berkebutuhan khusus. Namun, di sekolah yang sama ada guru yang sudah memberikan layanan pendidikan dengan baik terhadap peserta didik berkebutuhan khusus. Hal tersebut menunjukkan bahwa pendidikan inklusi yang berlangsung di sekolah tersebut belum sepenuhnya berjalan baik, karena belum sepenuhnya guru memberikan layanan pendidikan yang baik terhadap peserta didik berkebutuhan khusus dimana hal ini berkaitan dengan pemahaman yang dimiliki oleh guru terhadap peserta didik berkebutuhan khusus. Maka dari itu peneliti berkeinginan untuk meneliti lebih lanjut tentang pemahaman guru terhadap peserta didik berkebutuhan khusus di SDN penyelenggara pendidikan inklusi lainnya di Kepulauan Seribu guna mengetahui bagaimana pemahaman guru terhadap peserta didik berkebutuhan khusus di sekolah penyelenggara pendidikan inklusi lainnya di daerah tersebut.

Dari latar belakang masalah, maka dapat dirumuskan masalahnya adalah "Bagaimana pemahaman guru terhadap peserta didik berkebutuhan khusus di SDN inklusif di wilayah Kepulauan Seribu?".

Setelah penelitian selesai diharapkan dapat bermanfaat bagi pihak yang terkait yaitu: (1) Sekolah, Sebagai informasi dan masukan bagi sekolah tentang gambaran pemahaman guru terhadap peserta didik berkebutuhan khusus. (2) Guru, sebagai informasi bagi guru untuk meningkatkan pelayanan pendidikan peserta didik berkebutuhan khusus. Sehingga pemahaman guru terhadap peserta didik berkebutuhan khusus di Kepulauan Seribu akan lebih baik dan penyelenggaraan pendidikan inklusif lebih ideal. (3) Mahasiswa PLB, menginformasikan kepada mahasiswa didik PLB yang nantinya akan bekerja di sekolah inklusif dalam berkolabolasi dan memposisikan diri sebagai orang yang paham dibandingkan dengan guru yang bukan lulusan PLB. (4) Pemerintah, memberikan informasi tentang gambaran pemahaman guru, sehingga pemerintah dapat melihat sejauh mana pemahaman guru terhadap 
peserta didik berkebutuhan khusus. (5) Peneliti selanjutnya, memberikan acuan bagi peneliti selanjutnya untuk melakukan penelitian lanjutan.

Pemahaman merupakan satu dari enam aspek dalam ranah kognitif. Pemahaman seseorang didapat setelah seseorang tersebut sebelumnya mendapat pengetahuan. Menurut Peter W. Airasian dkk yang merevisi buku Benjamin Samuel Bloom M.D tentang taksonomi (2014:106) menyatakan bahwa proses-proses kognitif dalam memahami meliputi menafsirkan, mencontohkan, mengklasifikasikan, merangkum, menyimpulkan, membandingkan dan menjelaskan. Sedangkan menurut Chaplin yang dikutip Muhibbinsyah dalam buku Psikologi Belajar (2004:22), pemahaman termasuk ke ranah kognitif, dimana ranah kognitif merupakan salah satu domain wilayah atau ranah psikologis manusia yang meliputi setiap perilaku mental yang berhubungan dengan pemahaman, pertimbangan, pengolahan informasi, pemacahan masalah dan keyakinan. Seseorang untuk mendapatkan pemahaman harus mampu melewati beberapa aspek dari pemahaman dan hal tersebut berpengaruh dengan sikapnya dalam kehidupan.

Pendapat lain mengenai pengertian pemahaman juga dikemukakan oleh Benjamin Bloom yang dikutip oleh Nana Sudjana dalam buku Penilaian Hasil Belajar Mengajar (1990:24), menurutnya pemahaman merupakan ranah kognitif dimana pemahaman merupakan tingkat yang lebih tinggi dari pengetahuan. Sehingga menurut taksonomi Bloom, pemahaman mencakup kemampuan untuk menangkap makna dan arti. Selain itu kesanggupan memahami setingkat lebih tinggi dari pada pengetahuan. Namun tidak berarti bahwa pengetahuan tidak perlu ditanyakan, sebab untuk dapat memahami terlebuh dahulu perlu mengetahui atau mengenal lalu mengingatnya. Menurut Ngalim Purwanto (2001:44), pemahaman sebagai kemampuan untuk memahami arti atau konsep, situasi, serta fakta yang diketahuinya.

Menurut beberapa pendapat ahli, maka dapat disimpulkan bahwa pemahaman adalah tingkatan pola pikir seseorang, yang berada diatas pengetahuan. Dimana pemahaman adalah kemampuan dalam mengerti serta menjelaskan sesuatu yang diperoleh berdasarkan pengetahuan serta ingatan yang telah dimiliki, bahkan mampu menerapkan dalam situasi tertentu.

Salah satu komponen yang paling penting dalam sekolah inklusif adalah guru. Guru adalah semua orang yang berwenang dan bertanggung jawab terhadap pendidikan semua peserta didiknya juga membimbing dan membina semua peserta didik. Seorang guru adalah orang yang memiliki ilmu, yang mampu menangkap hakikat sesuatu, orang yang mampu menjelaskan hakikat dalam pengetahuan yang diajarkannya. Guru harus memiliki ilmu yang cukup untuk mengajarkan kepada peserta didiknya. Profesi sebagai guru menuntut seseorang untuk kreatif sehingga peserta didik yang diajarkannya akan lebih mudah memahami pelajaran.

Guru membantu peserta didik yang sedang berkembang untuk mempelajari sesuatu yang belum diketahuinya, membentuk kompetensi, dan memahami materi standar yang dipelajari. Jadi dapat disimpulkan bahwa guru adalah seorang yang mempunyai ilmu terhadap pendidikan dan berwenang serta bertanggung jawab terhadap semua yang dilakukan peserta didik. Guru juga dituntut kreatif dan memiliki peran penting terhadap keberhasilan tercapainya tujuan pendidikan di Indonesia.

Sebagai seorang guru yang akan mengajar peserta didik berkebutuhan 
khusus, maka artian guru disini juga adalah seorang guru yang memberikan layanan pendidikan kepada peserta didik berkebutuhan khusus dengan baik. Menurut Peraturan Menteri Negara Pemberdayaan Perempuan dan Perlindungan Anak RI, peserta didik berkebutuhan khusus adalah anak yang mengalami keterbatasan atau keluarbiasaan baik fisik, mental-intelektual, sosial, maupun emosional yang berpengaruh secara signifikan dalam proses pertumbuhan dan perkembangannya dibandingkan dengan anak-anak lain seusianya.

Dalam proses pembelajaran kebutuhan peserta didik berkebutuhan khusus juga berbeda-beda, ada yang lamban dan ada yang terlalu cepat dalam memahami pelajaran. Hal ini mengakibatkan peserta didik berkebutuhan khusus memerlukan layanan yang spesial dibanding anak pada umumnya. Ada beberapa jenis peserta didik berkebutuhan khusus yang biasanya bersekolah di sekolah inklusif yaitu diantaranya, anak dengan gangguan penglihatan, anak dengan gangguan pendengaran, anak dengan gangguan intelektual, anak dengan hambatan fisik dan motorik, anak dengan gangguan emosi dan tingkah laku, anak autis, anak kesulitan belajar, dan anak berbakat. Dari setiap jenis anak berkebutuhan khusus yang telah disebutkan, mereka mempunyai karakteristik yang berbeda dan membutuhkan layanan yang berbeda. Mereka juga membutuhkan strategi dan metode pembelajaran yang berbeda saat belajar. Setiap dari peserta didik berkebutuhan khusus juga harus selalu di asesmen secara berkala, agar memudahkan guru dalam melayani mereka sesuai dengan kebutuhannya.

Peserta didik berkebutuhan khusus dapat bersekolah di sekolah inklusif, agar memudahkan mereka dalam mengenyam pendidikan. Pendidikan inklusi diharapkan dapat menjadi jawaban dari keresahan berbagai pihak terhadap potret pendidikan Indonesia, dimana pendidikan menjadi hal yang sulit dijangkau oleh beberapa kalangan. Persepsi orang mengenai konsep pendidikan inklusi bermacam-macam. Konsep pendidikan inklusi merupakan antitesis dari penyelenggaraan pendidikan luar biasa yang segregatif dan eksklusif, yang memisahkan antara anak luar biasa dengan anak lain pada umumnya.

Istilah pendidikan inklusif digunakan untuk mendeskripsikan penyatuan anakanak berkelainan (penyandang hambatan/cacat) ke dalam program sekolah. Konsep inklusi memberikan pemahaman mengenai pentingnya penerimaan anak-anak yang memiliki hambatan ke dalam kurikulum, lingkungan, dan interaksi sosial yang ada di sekolah.

Pendidikan inklusif adalah proses pembelajaran yang ditujukan untuk mengatasi permasalahan pendidikan bagi anak yang berkebutuhan khusus dalam sekolah umum (reguler), dengan menggunakan sumber daya yang ada untuk menciptakan kesempatan bagi persiapan mereka hidup didalam masyarakat. Penekanan dari pendidikan inklusif adalah pengkajian ulang dan perubahan sistem pendidikan agar dapat menyesuaikan diri pada peserta didik bukan lagi peserta didik yang selalu dituntut untuk mengikuti sistem yang ada.

\section{METODE PENELITIAN}

Penelitian menggunakan metode survei dengan teknik deskriptif. Metode ini memberikan deskripsi atau memberi gambaran terhadap objek yang diteliti melalui data sampel atau populasi sebagaimana adanya. Variabel yang akan diteliti yaitu pemahaman guru di sekolah 
dasar inklusif terhadap peserta didik berkebutuhan khusus. Tempat penelitian dilakukan Sekolah Dasar Negeri Penyelenggara Pendidikan Inklusif di wilayah Kepulauan Seribu. Penelitian dilakukan pada bulan Januari-Juni 2017. Dengan melalui tahapan: mengumpulkan data dan fakta, mengajukan Proposal Penelitian, (c) mempersentasikan proposal dalam seminar usulan penelitian, (d) menyusun instrument penelitian, (e) mengurus izin penelitian, (f) pelaksanaan penelitian, $(\mathrm{g})$ pengolahan data, (h) laporan hasil penelitian.

Populasi dalam penelitian ini adalah 15 SDN Inklusif wilayah Kepulauan Seribu. Penentuan sampel dilakukan dengan teknik multistage. Pada teknik ini, peneliti mengambil sampel sekolah secara purposive, dikarenakan peneliti menimbang sekolah-sekolah di kepulauan seribu yang menjadi sekolah percontohan dan kemudian mengambil sampel guru secara seadanya, artinya peneliti melakukan penelitian kepada semua guru sekolah dasar inklusif. Sampel yang digunakan dalam penelitian ini adalah guru SDN penyelenggara pendidikan inklusif, yaitu SDN 01 Pulau Panggang, SDN 02 Pulau Panggang, SDN 03 Pulau Panggang, Kepulauan Seribu Utara yang di sekolahnya terdapat anak berkebutuhan khusus, dimana jumlah respondennya sebanyak 50 orang guru.

Pembuatan kisi-kisi intrumen dibuat dalam bentuk angket tertutup dengan menggunakan Skala Guttman sebagai tipe skala untuk mengungkapkan pemahaman guru terhadap peserta didik berkebutuhan khusus. Tipe skala ini nantinya akan mendapatkan jawaban yang jelas dan tegas terhadap pemahaman guru terhadap peserta didik berkebutuhan khusus. Skor yang diberikan untuk jawaban benar diberi skor 1 dan skor yang diberikan untuk jawaban salah diberi skor 0 .
Untuk teknik analisis data dilakukan dengan analisis statistika deskriptif. Data yang sudah didapatkan diolah sesuai pendekatan penelitian survei kuantitatif berupa data statistik dasar, yaitu: rata-rata (mean), nilai tengah (median), modus, stadar deviasi, skor maksimal, dan skor minimal, kemudian dianalisis menggunakan batas lulus ideal pada skor keseluruhan responden.

Batas lulus ideal digunakan sebagai batas penerimaan dalam pemberian status atau label sesuai dan tidak sesuai dengan kriteria pemahaman yang baik mengenai pemahaman guru terhadap peserta didik berkebutuhan khusus. Kriteria penerimaan pemahaman guru terhadap peserta didik berkebutuhan khusus sudah sesuai kriteria artinya guru paham terhadap karakteristik peserta didik berkebutuhan khusus atau belum sesuai kriteria artinya guru belum paham terhadap karakteristik peserta didik berkebutuhan khusus. Apabila responden memperoleh skor melebihi dari batas skor ideal, maka sudah sesuai kriteria artinya guru paham terhadap karakteristik peserta didik berkebutuhan khusus. Begitu juga sebaliknya apabila skor yang diperoleh responden kurang dari batas skor ideal, maka belum sesuai dengan kriteria artinya guru belum paham terhadap karakteristik peserta didik berkebutuhan khusus.

\section{HASIL DAN PEMBAHASAN}

Setelah dilakukan penelitian dan telah dianalisis maka didapatkan hasil dari 50 orang responden, sebanyak 36 orang guru sudah memahami peserta didik berkebutuhan khusus dan sebanyak 14 orang guru belum memahami peserta didik berkebutuhan khusus. Sedangkan hasil berdasarkan sekolah, dari SDN 01 Pulau Panggang yang jumlah respondennya sebanyak 22 orang, sebanyak 16 orang guru sudah memahami peserta didik berkebutuhan khusus dan sebanyak 6 orang 
guru belum mehamami peserta didik berkebutuhan khusus. Untuk SDN 02 Pulau Panggang yang jumlah respondennya sebanyak 17 orang, sebanyak 16 orang guru sudah memahami pesera didik berkebutuhan khusus dan 1 orang guru belum memahami peserta didik berkebutuhan khusus. Untuk SDN 03 Pulau Panggang yang jumlah respondennya sebanyak 11 orang, sebanyak 4 orang guru sudah memahami peserta didik berkebutuhan khusus dan sebanyak 6 orang guru belum memahami peserta didik berkebutuhan khusus. Selain melihat hasil dari keseluruhan sekolah dan masing-masing sekolah, peneliti juga melihat hasil dan menganalisis data dari perdimensi, dimana dimensi yang digunakan yaitu dimensi ingatan guru terhadap peserta didik berkebutuhan khusus dan dimensi pengetahuan guru terhadap peserta didik berkebutuhan khusus. Dari analisis data didapatkan bahwa guru lebih menguasai didimensi pengetahuan guru terhadap peserta didik berkebutuhan khusus, sedangkan untuk dimensi ingatan guru terhadap peserta didik berkebutuhan khusus guru masih belum banyak yang menguasainya.

Dari hasil dan pembahasan maka implikasi dari penelitian ini berdampak kepada pelayanan guru terhadap peserta didik berkebutuhan khusus di sekolah inklusif. Selain itu, kepada stakeholder (pemerintah) dimana stakeholder bertugas untuk meratakan pemahaman guru terhadap peserta didik berkebutuhan khusus di Sekolah dasar Inklusif wilayah Kepulauan Seribu agar terciptanya Sekolah Inklusif yang baik, terutama pada dimensi ingatan guru yang didalamnya terdapat definisi, faktor penyebab, dan karakteristik peserta didik berkebutuhan khusus.

\section{PENUTUP}

Dari hasil dan pembahasan yang telah dijabarkan maka dapat disimpulkan bahwa pemahaman guru terhadap peserta didik berkebutuhan khusus di Sekolah Dasar Inklusif wilayah Kepulauan Seribu belum merata. Guru SDN 01 Pulau Panggang dan SDN 02 Pulau Panggang sudah memiliki pemahaman yang baik, namun guru di SDN 03 Pulau Panggang belum memiliki pemahaman yang baik terhadap peserta didik berkebutuhan khusus. Hal ini berarti ada ketidak meratanya layanan pendidikan yang diterima oleh peserta didik berkebutuhan khusus di wilayah Kepulauan Seribu. Maka dari itu peneliti menyarankan kepada: 1) Bagi jurusan pendidikan luar biasa agar menjalin kerja sama dengan sekolah dasar inklusif di wilayah Kepulauan Seribu, 2) Bagi sekolah baiknya menjalin kerja sama dengan beberapa ahli dibidang pendidikan luar biasa dan dinas pendidikan, 3) Bagi guru sebaiknya mengikuti pelatihan mengenai layanan pendidikan untuk peserta didik berkebutuhan khusus.

\section{DAFTAR PUSTAKA}

Anas Sudijono. 1995. Pengantar Evaluasi Pendidikan. Jakarta: PT. Raja Grafindo Persada.

Dedy Kustawan. 2012. Pendidikan Inklusi dan Implementasinya. Jakarta: Luxima.

Direktorat PSLB. 2007. Pedoman Umum Penyelenggaraan Pendidikan Inklusi. Jakarta: Dirjendikdasmen. 
Hamzah B. Uno dan Nina Lamatenggo. 2016. Tugas Guru dalam Pembelajaran. Jakarta: Bumi Aksara.

Mudjito dkk. 2012. Pendidikan Inklusif. Jakarta: Baduose Media.

Mulyasa. 2006. Menjadi Guru Profesional. Bandung: Remaja Rosdakarya.

Ngalim Purwanto. 2001. Prinsip-Prinsip dan Teknik Evaluasi Pengajaran. Bandung: PT. Remaja Rosdakarya.

Peter W. Airasian dkk. 2014. Kerangka Landasan untuk Pembelajaran, Pengajaran, dan Asesmen. Yogyakarta: Pustaka Pelajar.

Raflis Kosasi dan Soetjipto. 2009. Profesi Sharve. (n.d.). Special Education Inclusion. Retrieved from www.dairycounsilofca.org

Supriyadi dkk. 2012. Modul Pendidikan dan Latihan Profesi Guru. Jakarta: UNJ.

T. Sutjihati Somantri. 2012. Psikologi Anak Luar Biasa. Bandung: PT Refika Aditama.

Wahyu Sri Ambar Arum. 2005. Perspektif Pendidikan Luar Biasa dan Implikasinya bagi Penyiapan Tenaga Kependidikan. Jakarta: Departemen Pendidikan Nasional. Keguruan. Jakarta: Rineka Cipta. 